\title{
BMP7 mediates the anticancer effect of honokiol by upregulating p53 in HCT116 cells
}

\author{
RONG-XING LIU ${ }^{1,2 *}$, WEN-YAN REN ${ }^{1,2^{*}}$, YAN MA ${ }^{1,2}$, YUN-PENG LIAO $^{1,2}$, HAN WANG $^{1,2}$, \\ JIA-HUI ZHU ${ }^{1,2}$, HAI-TAO JIANG ${ }^{2,3}$, KE WU $^{1,2}$, BAI-CHENG HE ${ }^{1,2}$ and WEN-JUAN SUN ${ }^{1,2}$ \\ ${ }^{1}$ Department of Pharmacology, School of Pharmacy, Chongqing Medical University; ${ }^{2}$ Key Laboratory for Biochemistry \\ and Molecular Pharmacology of Chongqing, Chongqing Medical University; ${ }^{3}$ Department of Orthorpedic, \\ The Second Affiliated Hospital of Chongqing Medical University, Chongqing 400016, P.R. China
}

Received April 20, 2017; Accepted July 14, 2017

DOI: $10.3892 /$ ijo.2017.4078

\begin{abstract}
Colorectal cancer (CRC) is the second leading cause of cancer death. Hence, there is a great need to explore new efficacious drugs for the treatment of CRC. Honokiol (HNK), a natural product extracted from magnolia bark, processes various biological activities, including anticancer. In this study, we introduced cell viability assay, western blotting, real-time PCR and immunofluorescent staining to determine the anticancer effect of HNK, and the possible mechanism underlying this biological process. We found that HNK can inhibit the proliferation and induce apoptosis in HCT116 cells in a concentration- and time-dependent manner. HNK activates p53 in HCT116 and other colon cancer cells. Exogenous p53 potentiates the anticancer of HNK, while p53 inhibitor decreases this effect of HNK. Moreover, HNK upregulates the expression of bone morphogenetic protein 7 (BMP7) in colon cancer cells; Exogenous BMP7 enhances the anticancer activity of HNK and BMP7 specific antibody reduces this effect of HNK. For mechanism, we found that HNK cannot increase the level of Smad1/5/8; Exogenous BMP7 potentiates the HNK-induced activation of p53. On the contrary, BMP7 specific antibody inhibits the HNK-induced activation of p53 in colon cancer cells and partly decreases the total level of p53. Our findings suggested that HNK may be a promising anticancer drug for CRC; activation of p53 plays an important role in the anticancer activity of HNK, which may be initialized partly by the HNK-induced upregulation of BMP7.
\end{abstract}

Correspondence to: Professors Wen-Juan Sun or Bai-Cheng He, Department of Pharmacology, School of Pharmacy, Chongqing Medical University, 1 Yixueyuan Road, Yuzhong, Chongqing 400016, P.R. China

E-mail: 1115494605@qq.com

E-mail: hebaicheng99@yahoo.com or 894704897@qq.com

*Contributed equally

Key words: honokiol, colon cancer, anti-proliferation, apoptosis, p53, bone morphogenetic protein 7

\section{Introduction}

Colorectal cancer (CRC) is one of the most common malignancies of gastrointestinal system (1). Although the treatment of CRC has been developed substantially in the past decades, the prognosis of CRC remains unsatisfactory $(2,3)$. Therefore, there is still an urgent clinical need to explore new and effective drugs for the treatment of CRC.

The traditional medicine (TM) and their derivatives is one of the most important source for anticancer drugs and multiple drugs from TM have been used for the treatment of CRC for decades, such as camptothecin, vincristine and paclitaxel (4-6). Honokiol (HNK) is a biphenolic natural product, which was extracted from the bark and leaves of Magnoliaplant spp (7). During the past decades, HNK has been extensively studied for its multiple pharmacological activities against several diseases such as anticancer, anti-oxidative, anti-angiogenesis, antiinflammatory and inhibition the transformation of malignant papillae to carcinomas in vitro and in vivo assays $(8,9)$. HNK may exerts such activities through various signaling pathways and molecules, such as STAT3, epidermal growth factor receptor (EGFR), nuclear factor- $\kappa \mathrm{B}(\mathrm{NF}-\kappa \mathrm{B})$, cell survival signaling, cell cycle, and inflammatory mediators (10-13). It has been reported that HNK shows anticancer activities in CRC (14-16), but the explicit mechanism under this effect remains unclear.

As a tumor suppressor, p53 has been targeted by various anticancer reagents. Evidence indicated that the anticancer activity of HNK can also be mediated by upregulating p53 in CRC (14), but how HNK regulates p53 is unknown. Bone morphogenetic proteins (BMPs) belong to the transforming growth factor- $\beta$ (TGF- $\beta$ ) super-family and plays an important role in regulating the proliferation and differentiation in epithelium of colon and rectum $(17,18)$. The aberrant signal of BMPs has been involved in the cause and progress of CRC $(19,20)$. BMPs can inhibit Wnt pathway p53-dependently (21). BMP7, as a member of BMPs, plays an important role in regulating the osteogenic differentiation in mesenchymal stem cells (22). Apart from this, it has been reported that BMP7 also possesses anticancer activity in $\mathrm{CRC}$, which may be mediated through the non-canonical BMPs/Smads pathway $(23,24)$. However, the concrete molecular mechanism need to be deciphered further. 
In this study, we determined the anticancer effect of HNK in HCT116 cells and analyzed the role of p53 or BMP7 in the anticancer activity of HNK. Moreover, we dissected the possible relationship between p53 and BMP7 in HCT116 cells.

\section{Materials and methods}

Cell culture and drug preparations. The HCT116 cell line was obtained from the American Type Culture Collection (ATCC; Manassas, VA, USA). Cells were cultured in Dulbecco's modified Eagle's medium (DMEM) with 10\% fetal bovine serum(FBS), $100 \mathrm{U} / \mathrm{ml}$ of penicillin and $100 \mu \mathrm{g} / \mathrm{ml}$ of streptomycin at $37^{\circ} \mathrm{C}$ with $5 \% \mathrm{CO}_{2}$. $\mathrm{HNK}$ was obtained from Hao-Xuan Bio-Tech Co., Ltd. (Xi'an, China) and dissolved with $\mathrm{DMSO}$ to $10 \mathrm{mmol} / \mathrm{l}$ as stock, stored at $-20^{\circ} \mathrm{C}$.

Cell proliferation assay. Cell proliferation and viability assay was measured with crystal violet staining and CCK-8 assay. Briefly, cells were plated at a density of 5000 cells per well in 96-well plates with $300 \mu \mathrm{l}$ medium in the presence of different concentrations of HNK for 24, 48 and $72 \mathrm{~h} .10 \mu \mathrm{l}$ CCK-8 per $100 \mu \mathrm{l}$ cell medium was added to each well and cells were incubated for $2 \mathrm{~h}$ at $37^{\circ} \mathrm{C}$. The optical absorbance of each well was measured with a microplate reader (BioTek, Winooski, VT, USA) at $450 \mathrm{~nm}$. Each assay was carried out in triplicate.

Flow cytometric analysis of cell cycle. Cells were seeded into 6-well plates and treated with different concentrations of HNK for $48 \mathrm{~h}$. Cells were collected and washed with phosphate buffered saline $\left(\mathrm{PBS}, 4^{\circ} \mathrm{C}\right)$, fixed with cold $\left(4^{\circ} \mathrm{C}\right) 70 \%$ ethanol, washed with 50\% ethanol, $30 \%$ ethanol and PBS sequentially. Finally, cells were stained with $1 \mathrm{ml}$ propidium iodide (PI, $20 \mathrm{mg} / \mathrm{ml}$ ) containing RNase $(1 \mathrm{mg} / \mathrm{ml})$ in PBS for $30 \mathrm{~min}$ and followed by flow cytometry analysis. Each assay was carried out in triplicate.

Annexin V-EGFP staining. Cells were cultured in 24-well plates and treated with different concentrations of HNK for 24 h. Cells were stained with Annexin V-EGFP Apoptosis Detection kits (KeyGen, Nanjing, China) according to the manufacturer's instructions. Briefly, cells were washed with cold PBS and then treated with $200 \mu \mathrm{l}$ binding buffer. Then, $2 \mu \mathrm{l}$ Annexin V-EGFP working solution was added to each well and incubated for $15 \mathrm{~min}$. Finally, the plate was washed extensively and images were taken with a fluorescent microscope. Each assay was carried out in triplicate.

Construction of the BMP7 and p53 recombinant adenovirus. The recombinant adenovirses were constructed with the AdEasy system (25). Briefly, the coding sequence (CDS) of human BMP7, p53 and green fluorescent protein (GFP) were amplified from the EST clone. Then, the fragments were cloned into shuttle vector pAdTrace, respectively. The shuttle vectors were linearized and transfected to HEK293 cells for the package of the recombinant adenoviruses, which were designated as AdBMP7 and Adp53. The recombinant adenoviruses were tagged with green GFP for tracking the viruses, and the recombinant adenovirus expressing GFP (AdGFP) only was used as vehicle control.
Table I. The primers used for PCR assay.

\begin{tabular}{ll}
\hline Gene & \multicolumn{1}{c}{ Primer sequence (5'-3') } \\
\hline GAPDH & F: CAACGAATTTGGCTACAGCA \\
& R: AGGGGAGATTCAGTGTGGTG \\
PCNA & F: GGCTCTAGCCTGACAAATGC \\
& R: GCCTCCAACACCTTCTTGAG \\
Bad & F: CGGAGGATGAGTGACGAGTT \\
& R: CGGAGGATGAGTGACGAGTT \\
P53 & F: GTCGGTGGGTTGGTAGTTTCTA \\
& R: AAAAAGAAATTGACCCTGAGCA \\
BMP7 & F: GGCAGGACTGGATCATCG \\
& R: AAGTGGACCAGCGTCTGC \\
\hline
\end{tabular}

F, forward; R, reverse

Immunofluorescent staining. Cells were plated into 48 -well plates and treated with different concentrations of HNK as design. Following treatment for $48 \mathrm{~h}$, cells were fixed with cold $\left(4^{\circ} \mathrm{C}\right)$ methanol for $15 \mathrm{~min}$, washed with cold PBS and permeablized with $0.5 \%$ Triton X-100. Cells were blocked with $5 \% \mathrm{BSA}$ at room temperature for $1 \mathrm{~h}$, followed by incubating with primary antibody for $\mathrm{p} 53$ or BMP7, the homologous IgG were used as negative control, followed by incubating with FITC-labeled anti-goat IgG for $1 \mathrm{~h}$. Finally, cells were stained with DAPI $(1 \mu \mathrm{g} / \mathrm{ml})$. The images were taken under an inverted microscope. Each assay was carried out in triplicate.

Reverse transcription $(R T)$ and real-time polymerase chain reaction (PCR) analysis. The cells were plated in T25 flask and treated with different concentration of HNK. At the scheduled time-point, total RNA were extracted with TRIzol reagent (Invitrogen, Carlsbad, CA, USA), and followed by RT reaction to generate cDNA template. The cDNA products were used as templates for real-time PCR to detect the expression level of target genes. All data of each sample were normalized with expression of glyceraldehyde-3-phosphate dehydrogenase (GAPDH). The primer sequences for this investigation are presented in Table I.

Western blot assay. Cells were seeded in 6-well plates and treated with different concentrations of HNK and/or combined with corresponding recombinant adenovirus or inhibitor. At the scheduled time point, all cells were lysed, collected and the lysates were denatured by boiling for $10 \mathrm{~min}$. All samples were subjected to electrophoresis with SDS-PAGE and transfered to polyvinylidene fluoride membranes, blotted with corresponding primary antibodies and the secondary antibodies conjugated with horseradish peroxidase successively. Then, the target proteins were developed with SuperSignal West Femto Substrate (\#34095, Thermo Scientific, Rockford, IL, USA). Each assay was done in triplicate.

Statistical analysis. The statistical analysis was performed with the Student's t-test between the control and the treatment 

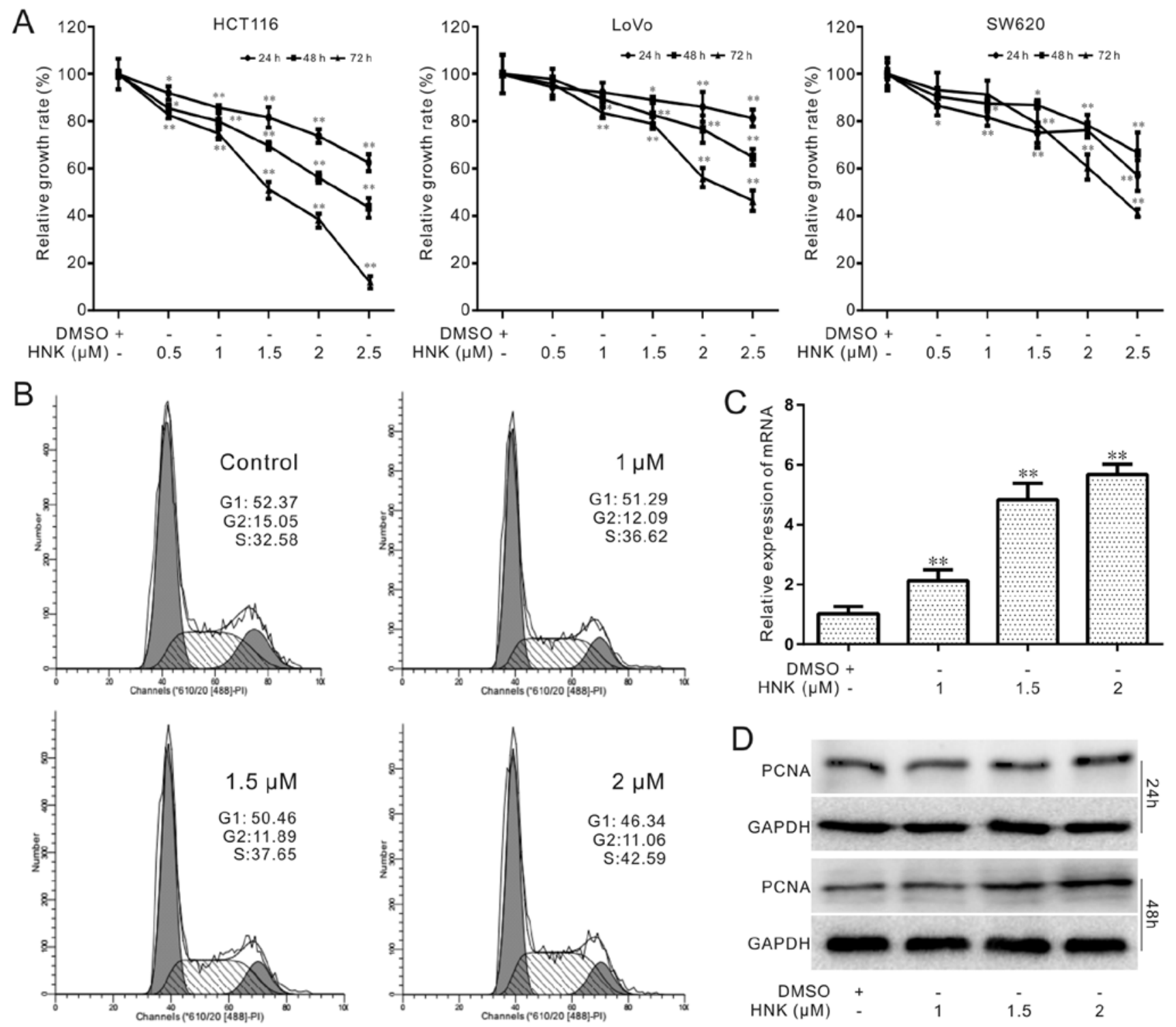

Figure 1. Effects of HNK on the proliferation of colon cancer cells. (A) CCK-8 assay results show the effect of HNK on the proliferation of colon cancer cells ("P<0.05 vs. control; ${ }^{* *} \mathrm{P}<0.01$ vs. control). (B) Flow cytometery analysis results show the effect of HNK on cell cycle arrest in HCT116 cells. (C) Real-time PCR assay results show the effect of HNK on the mRNA level of PCNA in HCT116 cells ( $48 \mathrm{~h} ;{ }^{* *} \mathrm{P}<0.01 \mathrm{vs}$. control). (D) Western blot assay results show the effect of HNK on the protein level of PCNA in HCT116 cells.

group. $\mathrm{P}<0.05$ was considered to indicate a statistically significant difference.

\section{Results}

Effects of HNK on the proliferation of colon cancer cells. In this study, we first tested the anti-proliferation effect of HNK in the three colon cancer cells HCT116, LoVo and SW620. The results showed HNK can inhibit the proliferation of all the three cell lines, and HCT116 cells are more susceptible to HNK (Fig. 1A). Therefore, we selected HCT116 cells for the following investigation. The cell cycle analysis results showed that HNK arrest cell cycle at G2 phase (Fig. 1B). The PCR and western blot analysis results showed that HNK increases the expression of the proliferation cell nuclear antigen (PCNA) in HCT116 cells (Fig. 1C and D). These data indicated HNK can inhibit the proliferation of colon cancer cells.
Effects of HNK on apoptosis in HCT116 cells. Next, we determined the effect of HNK on apoptosis in HCT116 cells. The PCR and western blot assay showed that HNK can upregulate the expression of Bad concentration-dependently (Fig. 2A and B). Flow cytometry analysis results showed that HNK can increase the ratio of apoptotic cells (Fig. 2C). The Annexin V-EGFP staining results showed that HNK can increase the apoptosis in HCT116 cells (Fig. 2D). These data suggested that HNK can induce apoptosis in colon cancer cells.

Effects of HNK on p53 in HCT116 cells. It is well known that p53 is a tumor suppressor, which has been the target of many anticancer agents. Therefore, we scheduled to determine whether p53 is involved in the anticancer effect of HNK in HCT116 cells. Western blot analysis results showed that HNK increases the level of p53-concentration-dependently, as well as the phosphorylation of p53 (Fig. 3A). The real-time 


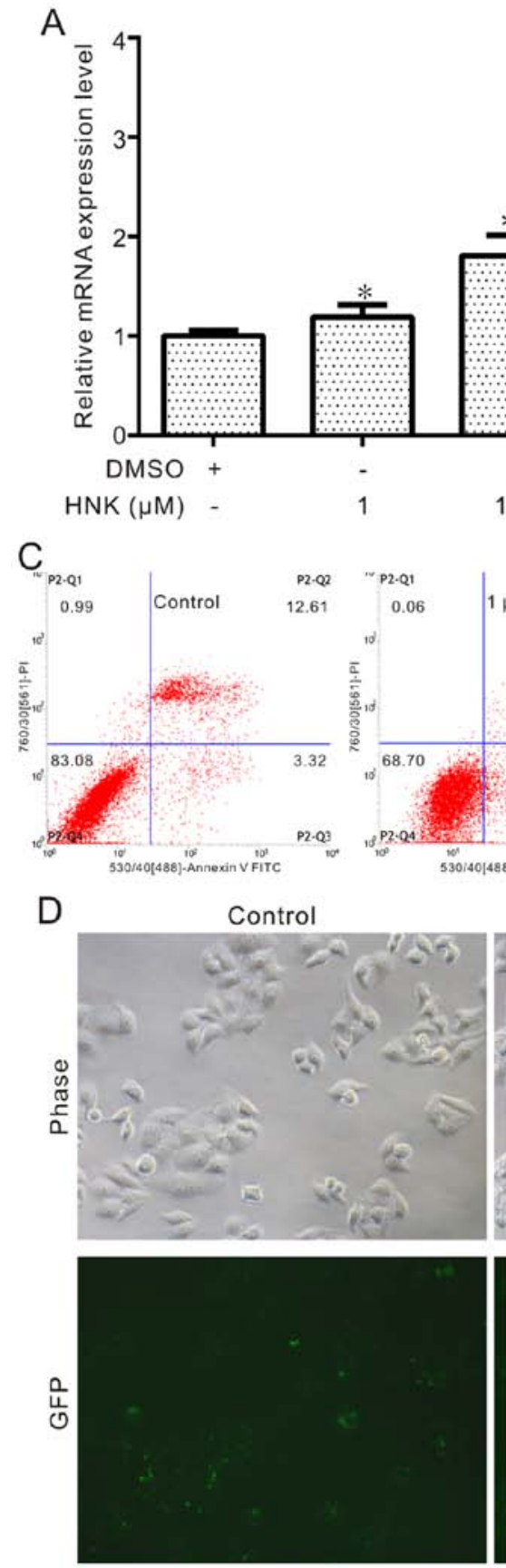

B
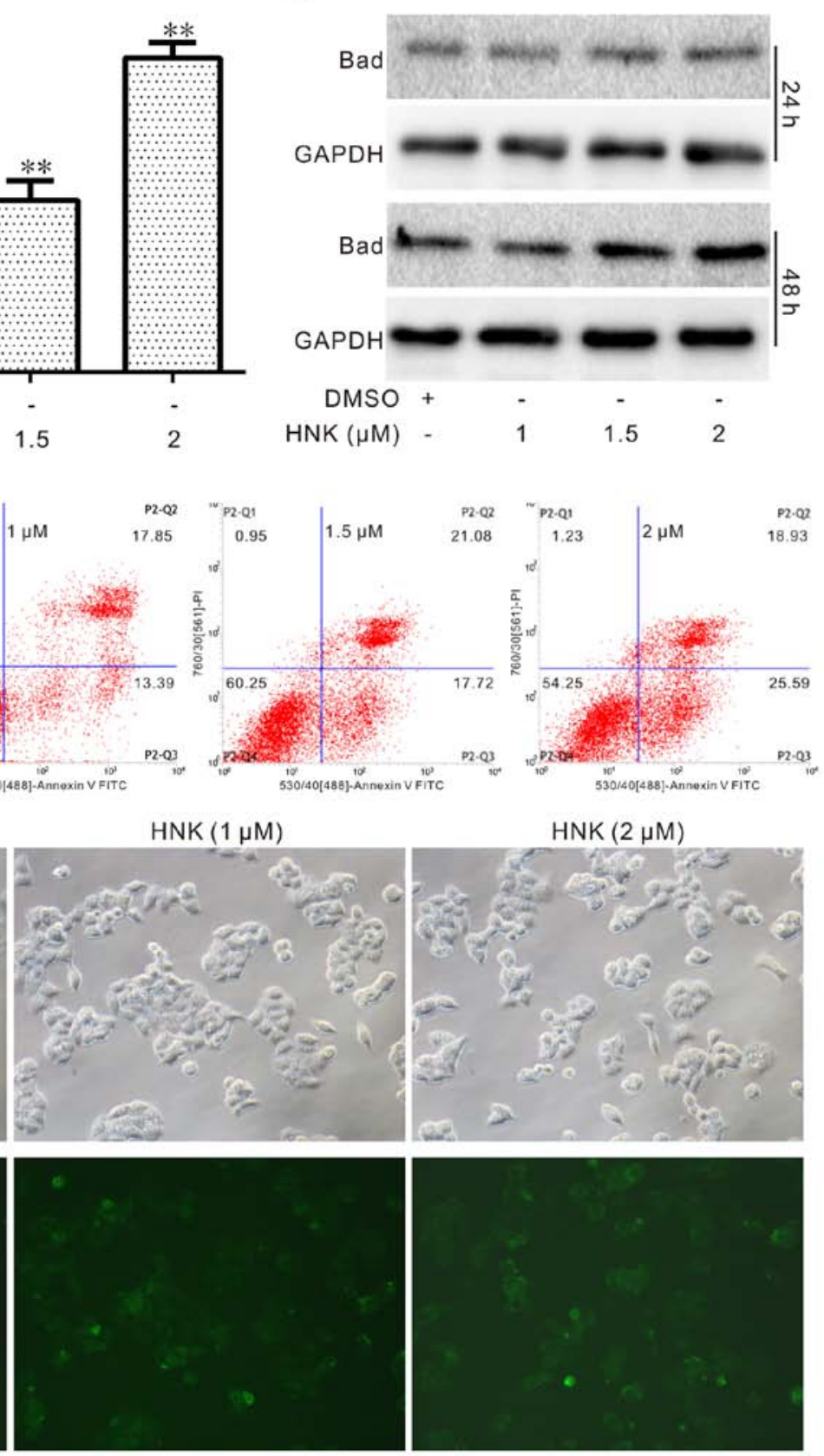

Figure 2. Effects of HNK on apoptosis in HCT116 cells. (A) Real-time PCR assay results show the effect of HNK on the mRNA level of Bad in HCT116 cells ( $48 \mathrm{~h} ;{ }^{*} \mathrm{P}<0.05$ vs. control; ${ }^{* *} \mathrm{P}<0.01$ vs. control). (B) Western blot assay results show the effect of HNK on the protein level of Bad in HCT116 cells. (C) Flow cytometry analysis results show the effect of HNK on inducing apoptosis in HCT116 cells. (D) Annexin V-EGFP staining results show apoptosis induced by HNK in HCT116 cells.

PCR assay results showed that HNK can also upregulate the mRNA expression of p53 in HCT116 cells (Fig. 3B). To confirm the effect of HNK on p53, we introduced immunofluorescent staining. The results recaptured the effect of HNK on increasing the level of p53 in HCT116 cells (Fig. 3C). With further western blot assay, we found the same effect of HNK on p53 in LoVo and SW620 colon cancer cells (Fig. 3D and E). All the data indicated that p53 may play an essential role in the anti-proliferation effect of HNK in HCT116 cells.

Effects of p53 on the anti-proliferation effect of HNK in colon cancer cells. We next evaluated the effect of p53 on the anticancer effect of HNK in the available colon cancer cells. The CCK-8 assay results showed that exogenous p53 or HNK can both inhibit the proliferation of HCT116 cells, while the combination of exogenous p53 can apparently enhance the anti-proliferation effect of HNK; specific inhibitor of p53 can not only partly increase the proliferation of HCT116 cells, but also greatly attenuate the anti-proliferation effect of HNK (Fig. 4A and B). Similar results were found in LoVo cells (Fig. 4C and D) and SW620 cells (Fig. 4E and F). These data suggested that p53 plays an important role in the antiproliferation effect of HNK in HCT116 cell, but how HNK upregulates p53 remains unknown. 

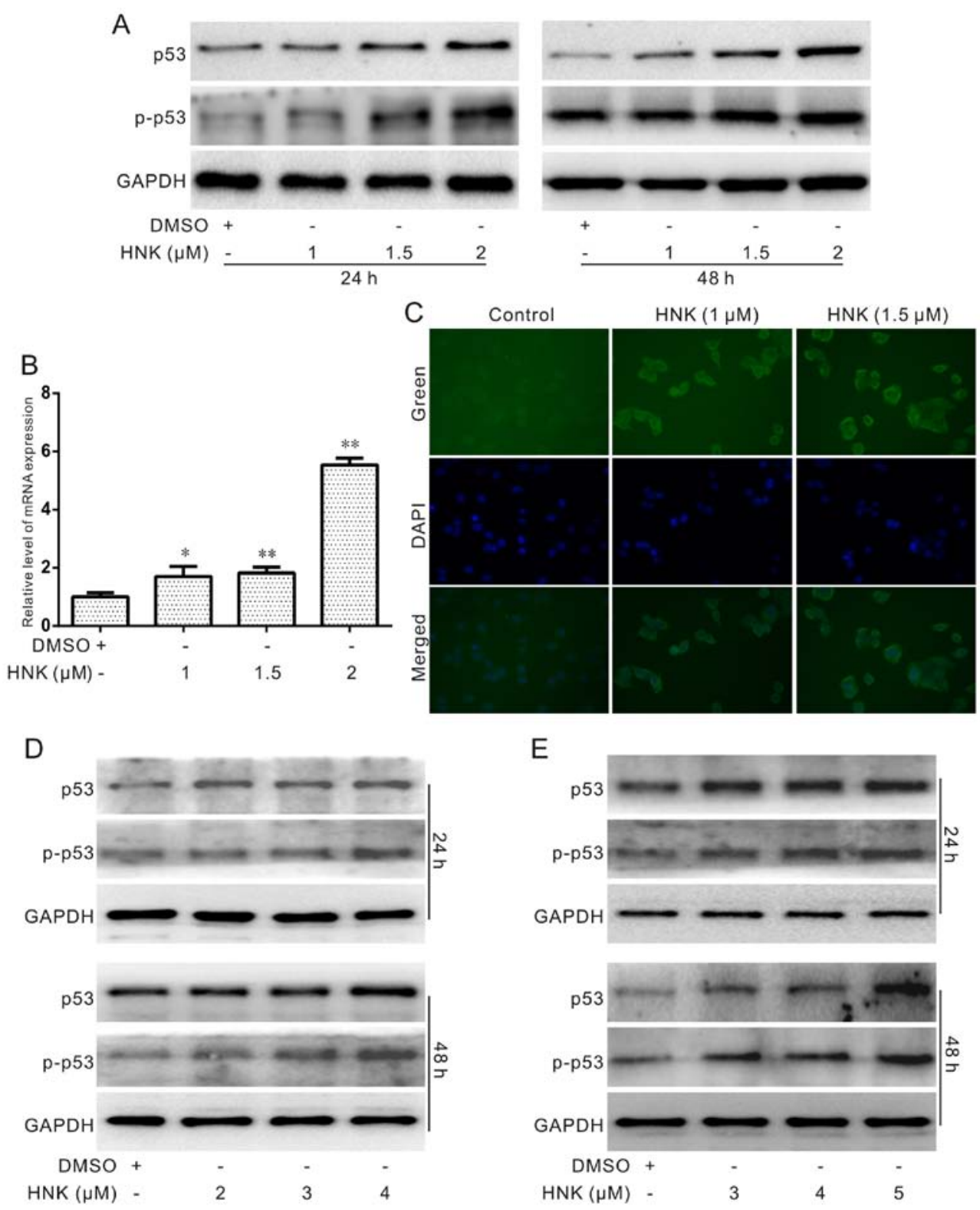

Figure 3. Effects of HNK on p53 in colon cancer cells. (A) Western blot assay results show the effect of HNK on the total or phophorylated level of p53 in HCT116 cells. (B) Real-time PCR assay results show the effect of HNK on the mRNA level of p53 in HCT116 cells ( $48 \mathrm{~h} ;{ }^{*} \mathrm{P}<0.05 \mathrm{vs}$. control; ${ }^{* *} \mathrm{P}<0.01 \mathrm{vs}$. control). (C) Immunofluorescent staining results show the effect of HNK on the level of p53 in HCT116 cells. (D) Western blot assay results show the effect of HNK on the total or phophorylated level of p53 in LoVo cells. (E) Western blot assay results show the effect of HNK on the total or phophorylated level of p53 in SW620 cells.

Effects of HNK on BMP7 in colon cancer cells. Although p53 may mediate the anti-proliferation effect of HNK in colon cancer cells, the mechanism underlying this process is unclear. Thus, we next tried to unveil how HNK upregulates p53 in colon cancer cells. BMPs is one of the sub-groups of TGF- $\beta$ super-family, which play an important role in regulating proliferation, and differentiation. Our previous studies demonstrated that exogenous BMP7 can inhibit the proliferation of colon cancer cells. Therefore, we determined whether HNK can affect the expression of BMP7 in HCT116 cells. The real-time PCR analysis results showed that HNK increases the mRNA expression of BMP7 notably (Fig. 5A). The western blot and immunofluorescent staining results confirmed that HNK can upregulate the expression of BMP7 in HCT116 cells (Fig. 5B and C). Western blot assay results showed the endogenous level of BMP7 in HCT116 cells is higher than that of FHC cells (Fig. 5D). Further analysis of the results exhibited that HNK can also increase the protein level of BMP7 in LoVo and SW620 cells (Fig. 5E and F). These data suggested that BMP7 may also be involved in the anti-proliferation effect of HNK in colon cancer cells.

Effects of BMP7 on the anti-proliferation effect of HNK in colon cancer cells. We next analyzed the effect of BMP7 on the anti-proliferation effect of HNK in HCT116 cells. The CCK-8 assay results showed that either HNK or exogenous BMP7 can inhibit the proliferation of HCT116 cell, but the BMP7 specific antibody can promote the proliferation of the cells; Combination of exogenous BMP7 enhances the antiproliferation effect of HNK, while the anti-proliferation effect 

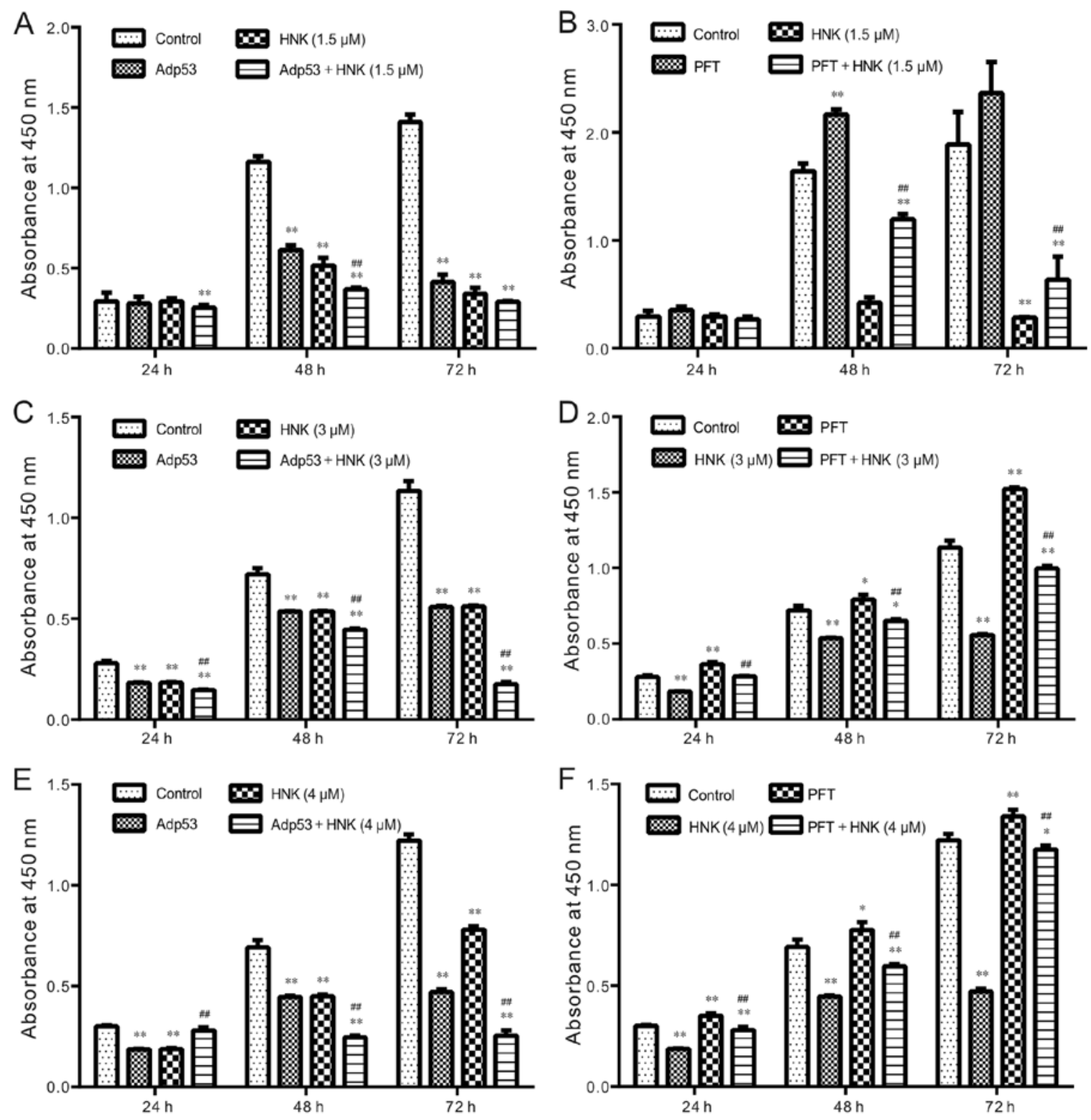

Figure 4. Effects of p53 on the anti-proliferation effect of HNK in HCT116 cells. (A) CCK-8 assay results show the effect of exogenous p53 on the antiproliferation effect of HNK in HCT116 cells ( ${ }^{* *} \mathrm{P}<0.01$ vs. control; ${ }^{\# \#} \mathrm{P}<0.01$ vs. the group treated with HNK only). (B) CCK-8 assay results show the effect of p53 specific inhibitor on the anti-proliferation effect of HNK in HCT116 cells $\left({ }^{* *} \mathrm{P}<0.01\right.$ vs. control; ${ }^{\# / P} \mathrm{P}<0.01$ vs. the group treated with HNK only; PFT: p53 inhibitor). (C) CCK-8 assay results show the effect of exogenous $\mathrm{p} 53$ on the anti-proliferation effect of $\mathrm{HNK}$ in LoVo cells $\left({ }^{* * *} \mathrm{P}<0.01 \mathrm{vs}\right.$. control; ${ }^{\# \#} \mathrm{P}<0.01 \mathrm{vs}$. the group treated with HNK only). (D) CCK-8 assay results show the effect of $\mathrm{p} 53$ specific inhibitor on the anti-proliferation effect of HNK in LoVo cells ("P<0.05 vs. control; ${ }^{* *} \mathrm{P}<0.01$ vs. control; ${ }^{* \#} \mathrm{P}<0.01$ vs. the group treated with HNK only; PFT: p53 inhibitor). (E) CCK-8 assay results show the effect of exogenous p53 on the anti-proliferation effect of HNK in SW620 cells $\left({ }^{* *} \mathrm{P}<0.01\right.$ vs. control; ${ }^{\# \#} \mathrm{P}<0.01$ vs. the group treated with HNK only). (F) CCK-8 assay results show the effect of p53 specific inhibitor on the anti-proliferation effect of HNK in SW620 cells ( $\mathrm{P}<0.05$ vs. control; ${ }^{* *} \mathrm{P}<0.01$ vs. control; ${ }^{* \#} \mathrm{P}<0.01$ vs. the group treated with HNK only; PFT: p53 inhibitor).

of HNK in HCT116 cells can be substantially reversed by the combination of BMP7 specific antibody (Fig. 6A and B). Simiar results were recaptured in LoVo cells (Fig. 6C and D) and SW620 cells (Fig. 6E and F). Therefore, these data indicated that the anti-proliferation effect of HNK may be partly mediated by upregulating BMP7 in colon cancer cells, but how BMP7 exerts such function remains unknown.

Effects of BMP7 on p53 affected by HNK in colon cancer cells. As BMPs usually exert their biological functions through BMPs/Smads pathway and HNK can upregulate the expression of BMP7, we first detected whether HNK can activate BMPs/Smads signal pathway in HCT116 cells. The western blot analysis results showed that there are no substantial change either on the total level of Smad1/5/8 or the level of phosphorylated Smad1/5/8 (Fig. 7A), which implied that the anti-proliferation effect of BMP7 may not be mediated through the canonical BMPs/Smads pathway. Since HNK upregulates p53 as well as BMP7, we speculated that BMP7 may be associated with the upregulation of p53 induced by HNK. Western blot assay results showed that exogenous BMP7 increases the level of total and phosphorylated p53 in HCT116 cells, which become more pronounced when combined with HNK (Fig. 7B). Specific antibody of BMP7 reduces the total 

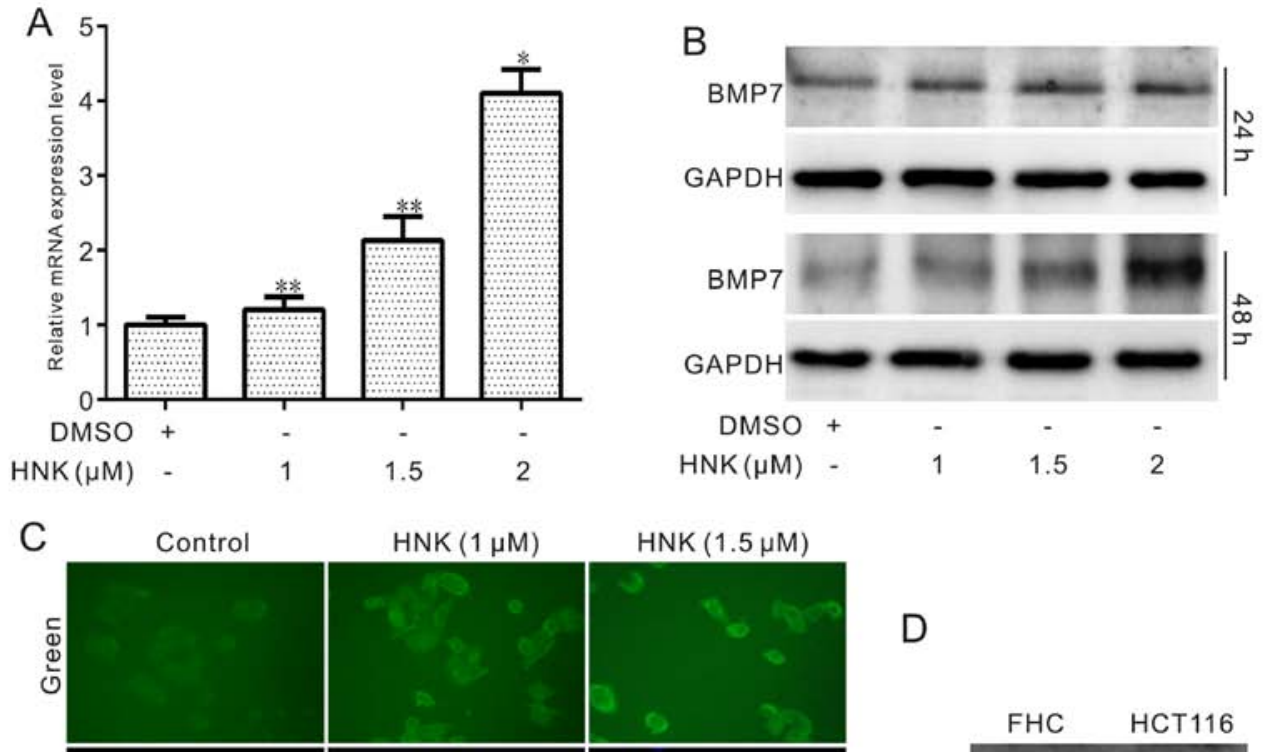

$\operatorname{HNK}(1.5 \mu \mathrm{M})$
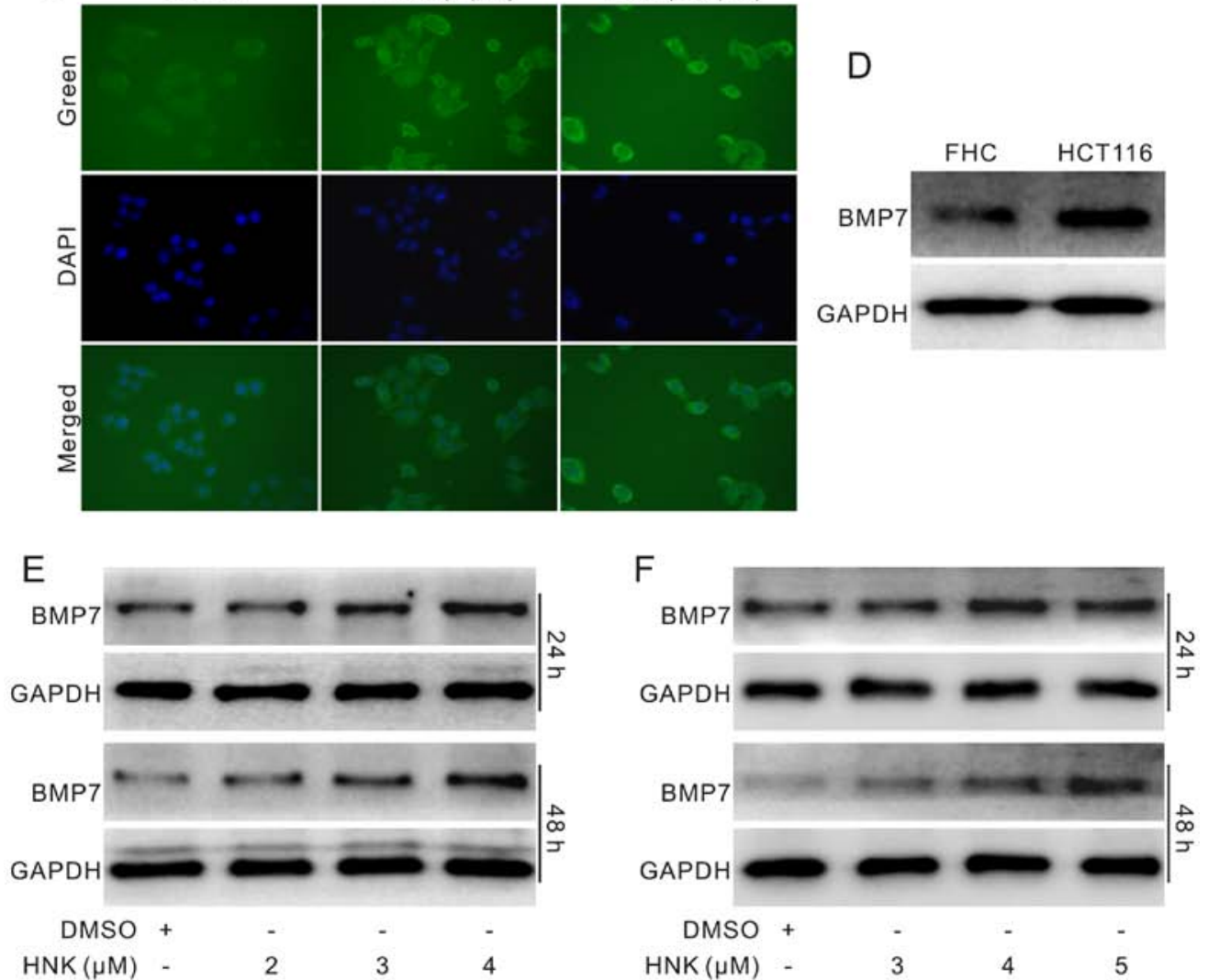

Figure 5. Effects of HNK on BMP7 in colon cancer cells. (A) Real-time PCR assay results show the effect of HNK on the mRNA level of BMP7 in HCT116 cells ( $48 \mathrm{~h} ;{ }^{*} \mathrm{P}<0.05$ vs. control; ${ }^{* *} \mathrm{P}<0.01$ vs. control). (B) Western blot assay results show the effect of HNK on the level of BMP7 in HCT116 cells. (C) Immunofluorescent staining results show the effect of HNK on the level of BMP7 in HCT116 cells. (D) Western blot analysis results show the endogenous expression level of BMP7 in FHC and HCT116 cells. (E) Western blot assay results show the effect of HNK on the level of BMP7 in LoVo cells. (F) Western blot assay results show the effect of HNK on the level of BMP7 in SW620 cells.

level of p53 and markedly decreases the level of phosphorylated p53 induced by HNK in HCT116 cells (Fig. 7C). Similar results showed that specific antibody of BMP7 can also decrease the total and phosphorylated level of p53 in LoVo and SW620 cells, respectively (Fig. 7D and E). These results strongly suggested that the effect of HNK on upregulating p53 may be partly mediated by the HNK-induced BMP7.

\section{Discussion}

HNK, as a phenolic compounds, is extracted from the bark and leaves of Chinese medicinal Magnolia plant spp. Increasing evidence indicated that HNK exhibits anticancer activity in various types of cancer cells, such as breast cancer, lung cancer, leukemia, colon cancer and other types of cancers (16,26-29). Therefore, HNK may be a promising candidate for chemotherapy. However, the explicit mechanism for this activity remains unclear. In the present study, we demonstrated that HNK can exert obvious anti-proliferation activity in colon cancer cells. Mechanically, we found that this effect of HNK in colon cancer cells may be partly mediated by the activation of $\mathrm{p} 53$, which may be resulted from the HNK-induced upregulation of BMP7. Our findings demonstrated that HNK may be a potential candidate drug for colon cancer, and BMP7 may be a plausible target for colon cancer treatment, although the mechanism of how HNK upregulates BMP7 remains unknown.

Colon cancer is one of the leading malignancies in alimentary system. Although the treatment for colon cancer 

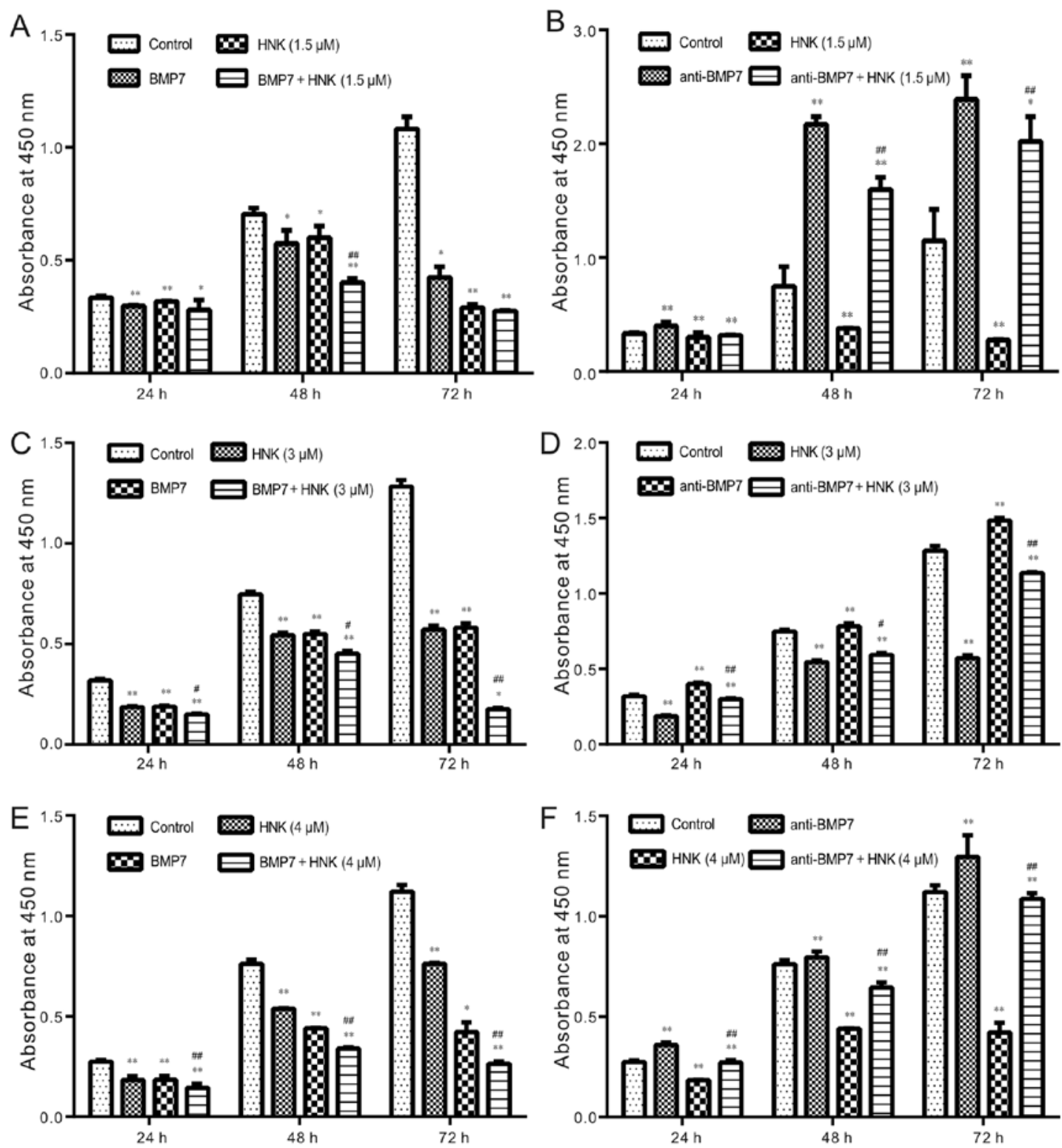

Figure 6. Effects of BMP7 on the anticancer effect of HNK in HCT116 cells. (A) CCK-8 assay results show the effect of exogenous BMP7 on the antiproliferation effect of HNK in HCT116 cells ( $\mathrm{P}<0.05$ vs. control; ${ }^{* *} \mathrm{P}<0.01$ vs. control; ${ }^{* \#} \mathrm{P}<0.01$ vs. the group treated with HNK only). (B) CCK-8 assay results show the effect of BMP7 specific antibody on the anti-proliferation effect of HNK in HCT116 cells ( $\mathrm{P}<0.05$ vs. control; ${ }^{* * *} \mathrm{P}<0.01$ vs. control; ${ }^{\# t} \mathrm{P}<0.01$ vs. the group treated with HNK only). (C) CCK-8 assay results show the effect of exogenous BMP7 on the anti-proliferation effect of HNK in LoVo cells ("P $<0.05$ vs. control; ${ }^{* *} \mathrm{P}<0.01$ vs. control; ${ }^{\#} \mathrm{P}<0.05$ vs. the group treated with HNK only, ${ }^{\# \#} \mathrm{P}<0.01$ vs. the group treated with HNK only). (D) CCK-8 assay results show the effect of BMP7 specific antibody on the anti-proliferation effect of HNK in LoVo cells ( ${ }^{* *} \mathrm{P}<0.01$ vs. control; ${ }^{\# \#} \mathrm{P}<0.01$ vs. the group treated with HNK only). (E) CCK-8 assay results show the effect of exogenous BMP7 on the anti-proliferation effect of HNK in SW620 cells ( $\mathrm{P}<0.05$ vs. control; ${ }^{* *} \mathrm{P}<0.01$ vs. control; ${ }^{\# \#} \mathrm{P}<0.01$ vs. the group treated with HNK only). (F) CCK-8 assay results show the effect of BMP7 specific antibody on the anti-proliferation effect of HNK in SW620 cells ( ${ }^{* *} \mathrm{P}<0.01$ vs. control; ${ }^{\# \#} \mathrm{P}<0.01$ vs. the group treated with HNK only).

have been developed greatly in the past decades, the prognosis remains unsatisfactory. There is still an urgent need to develop new and efficacious drugs for the treatment of colon cancer. Natural products and/or their derivates have been validated for colon cancer treatment for several decades, such as camptothecin, vincristine and paclitaxel (4-6). Therefore, the active compounds from natural product may also be an important source for chemotherapy agents. HNK, a biphenolic natural product isolated from the bark and leaves of Magnolia plant spp, has been demonstrated possessing excellent anticancer activity for various cancer cells (26). Our data also confirmed that HNK exerts efficacious anticancer effect in colon cells which suggested that HNK may be a potential anticancer agent for colon cancer. However, the mechanism underlying this biological function of HNK remains unknown. Multiple molecules and signals have been shown involved in the pathogenic cause of colon cancer, such as mutation in Wnt signal pathway, TP53 gene, and disfunction of TGF- $\beta$ pathway and PTEN (30-32). As a well-known tumor suppressor, p53 has shown function losses or mutation in colon cancer $(33,34)$. Therefore, p53 is thought as a classical target for the treatment of colon cancer. For this reason, we investigated whether HNK can affect the status of p53 in colon cells. The results showed that HNK obviously increases the level of p53; exogenous p53 enhances the anticancer effect of HNK obviously, while inhibition of p53 attenuates this 

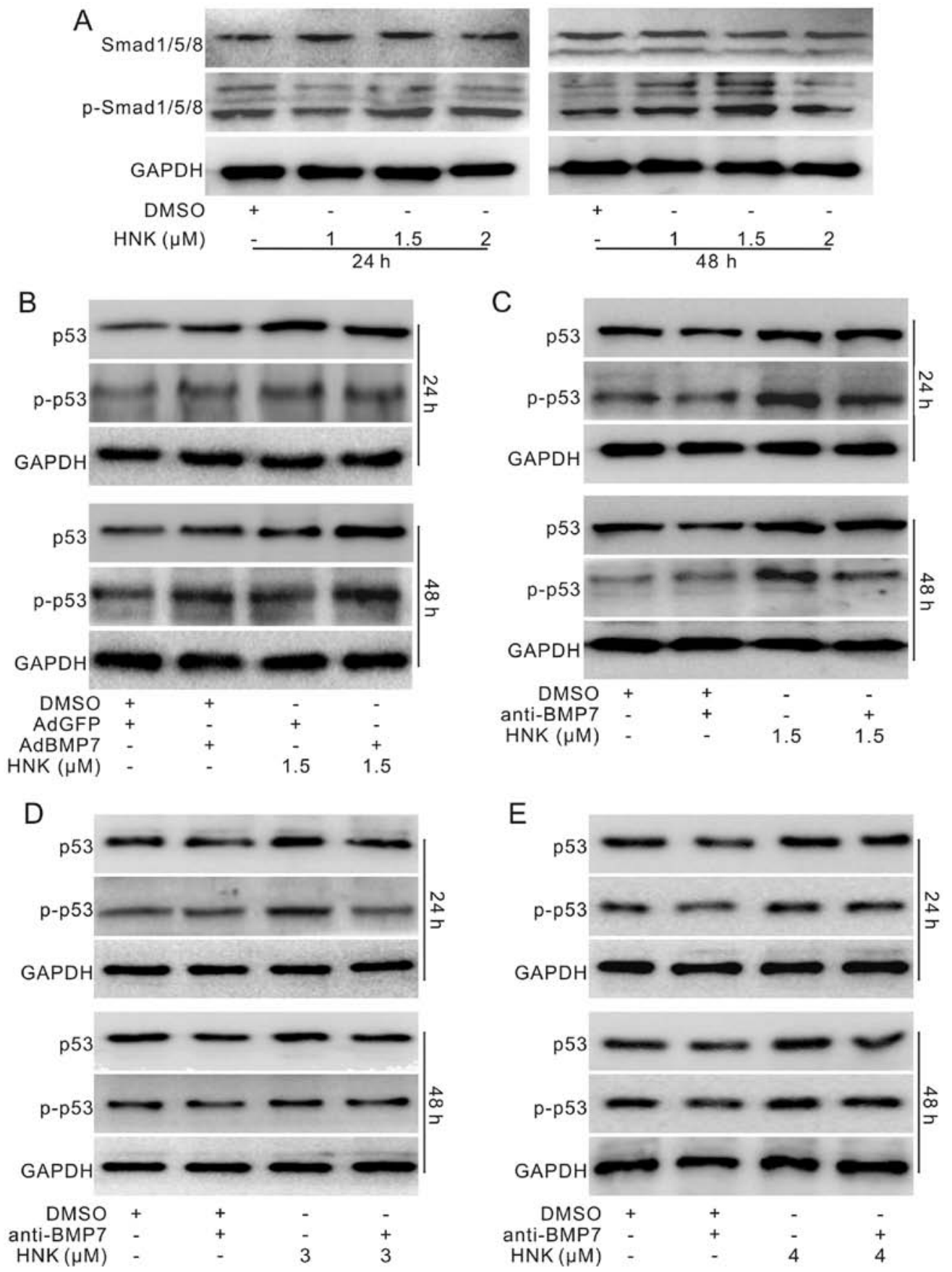

Figure 7. Effects of BMP7 on p53 in colon cancer cells. (A) Western blot assay results show the effect of HNK on the level of total or phosphorylated Smad1/5/8 in HCT116 cells. (B) Western blot assay results show the effect of exogenous BMP7 on p53 which were affected by HNK in HCT116 cells. (C) Western blot assay results show the effect of BMP7 specific antibody on p53 which were affected by HNK in HCT116 cells. (D) Western blot assay results show the effect of BMP7 specific antibody on p53 which were affected by HNK in LoVo cells. (E) Western blot assay results show the effect of BMP7 specific antibody on p53 which were affected by HNK in SW620 cells.

effect of HNK in HCT116, LoVo and SW620 cells. Therefore, the anti-proliferation activity of HNK in colon cancer cells may be mediated by the upregulation of p53, but how HNK activates p53 remains unclear.

Bone morphogenetic proteins (BMPs) belong to the super-family of transform growth factor- $\beta$ (TGF- $\beta$ ). BMPs play an important role in regulating proliferation and differentiation (35). BMPs usually exhibit their biological function through BMPs/Smads signal pathway called the canonical BMPs/Smads signal pathway. In this pathway, BMPs function as ligands to bind with the BMP receptors, including BMPRI and BMPRII.
It will recruit and phosphorylate BMPR1 when BMPR2 binds with corresponding ligands. Then, Smad1, Smad5 and Smad8 will become phosphorylated and form complex with Smad4. Finally, the complex translocates into nucleus and regulates the downstream targets $(36,37)$. It has been reported that the aberrant BMP signaling pathway is associated with the cause of colon cancer $(38,39)$. Mutations or disfunction of BMP pathway have been found in juvenile polyposis, an inherited polyposis syndrome that predisposes to colorectal cancer (40). BMP2 can inhibit the proliferation of colon cancer, inactivation of BMP3 is involved with the development of colon cancer and BMP9 
may mediate the anticancer effect of resveratrol in colon cancer cells (41-43). BMP7 is one of the BMPs members, also known as osteogenic protein-1 (OP-1). Increasing evidence indicated that BMP7 is also involved in cancer. The expression of BMP7 in breast cancer cells was higher than that of normal cells (44). Manning et al analyzed the tumor or normal samples from colon cancer patient with microarray and found that the mRNA level of BMP7 was twice in colorectal tumors than that of normal tissues (45). Our previous study demonstrated that Oridonin, an extract of active compound from the traditional Chinese medicine, exhibits efficacious anticancer activity against colon cancer through upregulating the expression of BMP7 (24). Thus, we speculated that the anticancer activity of HNK may also be related with BMP7. The PCR and western blot analysis results provided evidence that BMP7 is a target of HNK. The cell viability assay results indicated that upregulation of BMP7 may partly mediate the anti-proliferation activity of HNK in colon cancer. However, the explicit mechanism underlying this process is unknown.

It has been reported that BMP7 may exert the anticancer effect with a Smad4-independent pathway (46). It remains unknown whether BMP7 mediates the anti-proliferation of HNK in colon cancer in the same way. With western blot assay, we found that HNK exhibits no significant effect on the total and phosphorylated level of Smad1/5/8. This finding suggested that BMP7 may mediate the anti-proliferation effect of HNK through non-canonical BMPs/Smads pathway. However, the detail mechanism remains unclear. It has been reported that p53 and $\triangle \mathrm{Np} 63 \alpha$ may be a subset of TGF $\beta$ and BMPs regulated SMAD target genes in the mammary epithelium (47). In colorectal cancer, the effect of BMPs' signal on Wnt pathway may dependent on the status of Smad4 and p53 (21). BMP4 induced apoptosis in myeloma may also be mediated by p53 (48). The evidence suggested that the effect of BMP7 on the anti-proliferation activity of HNK in colon cancer may be mediated by p53. Our data demonstrated that HNK can also upregulate p53 in HCT116 and other colon cancer cells. Herein, we speculated that the HNK-induced upregulation of p53 may result from BMP7. With western blot assay, we found that exogenous expression of BMP7 can elevate the level of p53 induced by HNK, while it can be dramatically diminished by the specific antibody of BMP7 in HCT116, LoVo and SW620 cells. Therefore, the HNK-induced upregulation of p53 may result from BMP7, which is upregulated by HNK.

Taken together, our investigation demonstrated that HNK may be an efficacious anticancer agent for colon cancer. HNK-induced upregulation of p53 may partly mediate the anticancer activity of HNK, and the effect of HNK on p53 may depend on the upregulation of BMP7. The details about how HNK regulates the expression of BMP7 need to be intensively deciphered.

\section{Acknowledgements}

The authors would like to thank Professor Tong-Chuan He (Medical Center of the University of Chicago) for his generous provision of the recombinant adenoviruses. The present study was supported by research grants from the Natural Science Foundation of China (grants nos. NSFC 81372120 and 81572226 to B.-C. He).

\section{References}

1. Aghagolzadeh P and Radpour R: New trends in molecular and cellular biomarker discovery for colorectal cancer. World $\mathrm{J}$ Gastroenterol 22: 5678-5693, 2016.

2. Vinnakota K, Zhang Y, Selvanesan BC, Topi G, Salim T, SandDejmek J, Jönsson G and Sjölander A: M2-like macrophages induce colon cancer cell invasion via matrix metalloproteinases. J Cell Physiol: Jan 18, 2017 (Epub ahead of print).

3. Na H, Liu X, Li X, Zhang X, Wang Y, Wang Z, Yuan M, Zhang Y, Ren S and Zuo Y: Novel roles of DC-SIGNR in colon cancer cell adhesion, migration, invasion, and liver metastasis. J Hematol Oncol 10: 28, 2017.

4. Chazin EL, Reis RR, Junior WT, Moor LF and Vasconcelos TR: An overview on the development of new potentially active camptothecin analogs against cancer. Mini Rev Med Chem 14: 953-962, 2014.

5. Xie X, Tang B, Zhou J, Gao Q and Zhang P: Inhibition of the PI3K/Akt pathway increases the chemosensitivity of gastric cancer to vincristine. Oncol Rep 30: 773-782, 2013.

6. Baird RD, Tan DS and Kaye SB: Weekly paclitaxel in the treatment of recurrent ovarian cancer. Nat Rev Clin Oncol 7: 575-582, 2010.

7. Pan J, Lee Y, Wang Y and You M: Honokiol targets mitochondria to halt cancer progression and metastasis. Mol Nutr Food Res 60: 1383-1395, 2016.

8. Wu GJ, Lin CJ, Lin YW and Chen RM: Data analyses of honokiol-induced autophagy of human glioma cells in vitro and in vivo. Data Brief 9: 667-672, 2016.

9. Lu CH, Chen SH, Chang YS, Liu YW, Wu JY, Lim YP, Yu HI and Lee YR: Honokiol, a potential therapeutic agent, induces cell cycle arrest and program cell death in vitro and in vivo in human thyroid cancer cells. Pharmacol Res 115: 288-298, 2017.

10. Wen J, Wang X, Pei H, Xie C, Qiu N, Li S, Wang W, Cheng X and Chen L: Anti-psoriatic effects of Honokiol through the inhibition of NF- $\kappa$ B and VEGFR-2 in animal model of K14-VEGF transgenic mouse. J Pharmacol Sci 128: 116-124, 2015.

11. Prasad R and Katiyar SK: Honokiol, an active compound of magnolia plant, inhibits growth, and progression of cancers of different organs. Adv Exp Med Biol 928: 245-265, 2016.

12. Pan J, Lee Y, Zhang Q, Xiong D, Wan TC, Wang Y and You M: Honokiol decreases lung cancer metastasis through inhibition of the STAT3 signaling pathway. Cancer Prev Res (Phila) 10: 133-141, 2017.

13. Leeman-Neill RJ, Cai Q, Joyce SC, Thomas SM, Bhola NE, Neill DB, Arbiser JL and Grandis JR: Honokiol inhibits epidermal growth factor receptor signaling and enhances the antitumor effects of epidermal growth factor receptor inhibitors. Clin Cancer Res 16: 2571-2579, 2010.

14. Lai YJ, Lin CI, Wang CL and Chao JI: Expression of survivin and p53 modulates honokiol-induced apoptosis in colorectal cancer cells. J Cell Biochem 115: 1888-1899, 2014.

15. Ponnurangam S, Mammen JM, Ramalingam S, He Z, Zhang Y, Umar S, Subramaniam D and Anant S: Honokiol in combination with radiation targets notch signaling to inhibit colon cancer stem cells. Mol Cancer Ther 11: 963-972, 2012.

16. Wynn ML, Consul N, Merajver SD and Schnell S: Inferring the effects of honokiol on the notch signaling pathway in SW480 colon cancer cells. Cancer Inform 13 (Suppl 5): 1-12, 2014.

17. Hardwick JC, Van Den Brink GR, Bleuming SA, Ballester I, Van Den Brande JM, Keller JJ, Offerhaus GJ, Van Deventer SJ and Peppelenbosch MP: Bone morphogenetic protein 2 is expressed by, and acts upon, mature epithelial cells in the colon. Gastroenterology 126: 111-121, 2004.

18. Ji T, Takabayashi H, Mao M, Han X, Xue X, Brazil JC, Eaton KA, Shah YM and Todisco A: Regulation and function of bone morphogenetic protein signaling in colonic injury and inflammation. Am J Physiol Gastrointest Liver Physiol 312: G24-G33, 2017.

19. Slattery ML, Lundgreen A, Herrick JS, Kadlubar S, Caan BJ, Potter JD and Wolff RK: Genetic variation in bone morphogenetic protein and colon and rectal cancer. Int J Cancer 130: 653-664, 2012.

20. Voorneveld PW, Kodach LL, Jacobs RJ, Liv N, Zonnevylle AC, Hoogenboom JP, Biemond I, Verspaget HW, Hommes DW, de Rooij $\mathrm{K}$ et al: Loss of SMAD4 alters BMP signaling to promote colorectal cancer cell metastasis via activation of Rho and ROCK. Gastroenterology 147: 196-208.e13, 2014. 
21. Voorneveld PW, Kodach LL, Jacobs RJ, van Noesel CJ, Peppelenbosch MP, Korkmaz KS, Molendijk I, Dekker E, Morreau H, van Pelt GW, et al: The BMP pathway either enhances or inhibits the Wnt pathway depending on the SMAD4 and p53 status in CRC. Br J Cancer 112: 122-130, 2015.

22. Xue Z, Niu LY, An G, Guo YS, Lv SC and Ren XP: Expression of recombinant BMP-7 gene increased ossification activity in the rabbit bone mesenchymal stem cells. Eur Rev Med Pharmacol Sci 19: 3056-3062, 2015.

23. Hao Z, Yang X, Lv Y, Li S, Purbey BK and Su H: Intracolonically administered adeno-associated virus-bone morphogenetic protein-7 ameliorates dextran sulphate sodium-induced acute colitis in rats. J Gene Med 14: 482-490, 2012.

24. Ren CM, Li Y, Chen QZ, Zeng YH, Shao Y, Wu QX, Yuan SX, Yang JQ, Yu Y, Wu K, et al: Oridonin inhibits the proliferation of human colon cancer cells by upregulating BMP7 to activate p38 MAPK. Oncol Rep 35: 2691-2698, 2016.

25. Luo J, Deng ZL, Luo X, Tang N, Song WX, Chen J, Sharff KA Luu HH, Haydon RC, Kinzler KW, et al: A protocol for rapid generation of recombinant adenoviruses using the AdEasy system. Nat Protoc 2: 1236-1247, 2007.

26. Singh T and Katiyar SK: Honokiol, a phytochemical from Magnolia spp., inhibits breast cancer cell migration by targeting nitric oxide and cyclooxygenase-2. Int J Oncol 38: 769-776, 2011

27. Singh T and Katiyar SK: Honokiol inhibits non-small cell lung cancer cell migration by targeting $\mathrm{PGE}_{2}$-mediated activation of $\beta$-catenin signaling. PLoS One 8: e60749, 2013.

28. Li HY, Ye HG, Chen CQ, Yin LH, Wu JB, He LC and Gao SM: Honokiol induces cell cycle arrest and apoptosis via inhibiting class I histone deacetylases in acute myeloid leukemia. J Cell Biochem 116: 287-298, 2015.

29. Hahm ER, Karlsson AI, Bonner MY, Arbiser JL and Singh SV: Honokiol inhibits androgen receptor activity in prostate cancer cells. Prostate 74: 408-420, 2014

30. Markowitz SD and Bertagnolli MM: Molecular origins of cancer: Molecular basis of colorectal cancer. N Engl J Med 361: 2449-2460, 2009.

31. Mehlen P and Fearon ER: Role of the dependence receptor DCC in colorectal cancer pathogenesis. J Clin Oncol 22: 3420-3428, 2004

32. Jung B, Staudacher JJ and Beauchamp D: Transforming growth factor $\beta$ superfamily signaling in development of colorectal cancer. Gastroenterology 152: 36-52, 2017.

33. Yamada H, Shinmura K, Yamamura Y, Kurachi K, Nakamura T, Tsuneyoshi T, Yokota N, Maekawa $\mathrm{M}$ and Sugimura $\mathrm{H}$ : Identification and characterization of a novel germline p53 mutation in a patient with glioblastoma and colon cancer. Int J Cancer 125: 973-976, 2009.

34. Demir L, Ekinci N, Erten C, Somali I, Can A, Dirican A, Cokmert S, Bayoglu V, Akyol M, Kucukzeybek Y, et al: The impact of cell proliferation markers and p53 mutation status on prognosis of non-metastatic colon cancer. J Surg Oncol 109: 665-675, 2014
35. Murray SS, Brochmann Murray EJ, Wang JC and Duarte ME: The history and histology of bone morphogenetic protein. Histol Histopathol 31: 721-732, 2016.

36. Massagué J, Seoane J and Wotton D: Smad transcription factors. Genes Dev 19: 2783-2810, 2005.

37. Kawabata M, Imamura $T$ and Miyazono K: Signal transduction by bone morphogenetic proteins. Cytokine Growth Factor Rev 9: 49-61, 1998

38. Grijelmo C, Rodrigue C, Svrcek M, Bruyneel E, Hendrix A, de Wever O and Gespach C: Proinvasive activity of BMP-7 through SMAD4/src-independent and ERK/Rac/JNK-dependent signaling pathways in colon cancer cells. Cell Signal 19: 1722-1732, 2007.

39. Bertrand FE, Angus CW, Partis WJ and Sigounas G: Developmental pathways in colon cancer: Crosstalk between WNT, BMP, Hedgehog and Notch. Cell Cycle 11: 4344-4351, 2012.

40. Brosens LA, Langeveld D, van Hattem WA, Giardiello FM and Offerhaus GJ: Juvenile polyposis syndrome. World J Gastroenterol 17: 4839-4844, 2011

41. Zhang Y, Chen X, Qiao M, Zhang BQ, Wang N, Zhang Z, Liao Z, Zeng L, Deng Y, Deng F, et al: Bone morphogenetic protein 2 inhibits the proliferation and growth of human colorectal cancer cells. Oncol Rep 32: 1013-1020, 2014.

42. Loh K, Chia JA, Greco S, Cozzi SJ, Buttenshaw RL, Bond CE, Simms LA, Pike T, Young JP, Jass JR, et al: Bone morphogenic protein 3 inactivation is an early and frequent event in colorectal cancer development. Genes Chromosomes Cancer 47: 449-460, 2008.

43. Yuan SX, Wang DX, Wu QX, Ren CM, Li Y, Chen QZ, Zeng YH, Shao Y, Yang JQ, Bai Y, et al: BMP9/p38 MAPK is essential for the antiproliferative effect of resveratrol on human colon cancer. Oncol Rep 35: 939-947, 2016.

44. Alarmo EL, Pärssinen J, Ketolainen JM, Savinainen K, Karhu R and Kallioniemi A: BMP7 influences proliferation, migration, and invasion of breast cancer cells. Cancer Lett 275: 35-43, 2009.

45. Manning AM, Williams AC, Game SM and Paraskeva C: Differential sensitivity of human colonic adenoma and carcinoma cells to transforming growth factor beta (TGF-beta): Conversion of an adenoma cell line to a tumorigenic phenotype is accompanied by a reduced response to the inhibitory effects of TGF-beta. Oncogene 6: 1471-1476, 1991.

46. Beck SE, Jung BH, Fiorino A, Gomez J, Rosario ED, Cabrera BL, Huang SC, Chow JY and Carethers JM: Bone morphogenetic protein signaling and growth suppression in colon cancer. Am J Physiol Gastrointest Liver Physiol 291: G135-G145, 2006.

47. Balboni AL, Cherukuri P, Ung M, DeCastro AJ, Cheng $\mathrm{C}$ and DiRenzo J: p53 and $\Delta$ Np63 $\alpha$ coregulate the transcriptional and cellular response to TGF $\beta$ and BMP signals. Mol Cancer Res 13: 732-742, 2015.

48. Fukuda N, Saitoh M, Kobayashi N and Miyazono K: Execution of BMP-4-induced apoptosis by p53-dependent ER dysfunction in myeloma and B-cell hybridoma cells. Oncogene 25: 3509-3517, 2006. 